\title{
Anti-inflammatory and Anti-nociceptive Effects of Piperine in Gamma-irradiated Rats
}

\author{
M. A. El-Ghazaly, N. A. Fadel, E. R. Rashed and S. A. Kenawy* \\ Drug Radiation Research Dept., National Centre for Radiation \\ Research and Technology (NCRRT), Egyptian Atomic Energy \\ Authority, P. O. Box; 29 Nasr City, Egypt and "Pharmacology \\ Dept., Faculty of Pharmacy, Cairo University, Cairo, Egypt.
}

\begin{abstract}
DIPERINE is an alkaloid that is found naturally in plants belonging to the piperaceae family and has been reported to possess anti-inflammatory properties. The present study was constructed to investigate the possible anti-inflammatory and analgesic effects of piperine on different inflammatory models induced in irradiated rats. Paw volume and nociceptive threshold were measured in carrageenan-induced paw oedema and hyperalgesia model. Leukocytes count, tumour necrosis factor- $\alpha$ (TNF- $\alpha$ ), prostaglandin $\mathrm{E}_{2}\left(\mathrm{PGE}_{2}\right)$, thiobarbituric acid reactive substances (TBARs) and total nitrate/nitrite (NOx) were estimated in the exudate collected from six-day old air pouch model. Irradiated rats were exposed to 6Gy gamma $(\gamma)$-irradiation. Oral administration of piperine at a dose of $50 \mathrm{mg} / \mathrm{kg}$ resulted in a significant decrement in the paw volume and significant increment in the nociceptive threshold, in non-irradiated and irradiated rats. The inflammation induced in irradiated rats in the six-day old air pouch model increased all the estimated parameters in the exudate whereas; piperine decreased their elevation in non-irradiated and irradiated rats. Piperine possesses a potential anti-inflammatory and anti-nociceptive activity on inflammation induced in irradiated rats.
\end{abstract}

Keywords: Inflammation, gamma-irradiation, piperine, carrageenan, air pouch.

Inflammation is defined as the local response of living tissues to injury due to any agent; leading to the local accumulation of blood cells and fluids (Ryan and Majno, 1977). A common feature of inflammatory responses is that they are orchestrated by a wide range of inflammatory mediators which are released into the extracellular space by damaged tissue, recruited immune cells and even by the affected sensory fibres (Kumar et al., 2012 and Ryan, 1974). 
These chemical agents also have a key role in the development of the inflammatory pain where they are able to either sensitize or directly excite the peripheral terminals of nociceptive neurons (Keele, 1967 and Linley et al., 2010). Ionising radiation (IR) has been reported to exaggerate the inflammatory responses and to enhance the release of the inflammatory mediators (El-Ghazaly et al., 2010 $, 2010^{\mathrm{b}}, 2015$, Khayyal et al., 2009 and Yang et al., 2011).

Considerable emphasis has been given to identify new anti-inflammatory agents from natural sources, commonly known as nutraceuticals. It is a broad term used to describe any product derived from food sources that provides extra health benefits in addition to the basic nutritional value found in food (Brower, 1998 and Kalra, 2003).

Piperine is an alkaloid that is found naturally in plants belonging to the piperaceae family, such as Piper nigrum $L$, commonly known as black pepper, and Piper longum L, commonly known as Long pepper. Piperine has been reported to possess an anti-inflammatory activity in several studies (Bang et al., 2009, Mujumdar et al., 1990, Murunikkara et al., 2012, Sabina et al., 2011 and Umar et al., 2013).

Our study was constructed to evaluate the possible anti-inflammatory activity of piperine in different inflammatory models induced in gammairradiated rats. In addition, our study was extended to evaluate its possible analgesic activity.

\section{Materials and Methods}

\section{Animals}

Male Wistar albino rats, weighing 120-150g, were purchased from the animal breeding house of National Research Centre, Giza, Egypt. Rats were acclimatized in the animal facility of NCRRT for at least one week before subjecting them to experimentation. They were fed standard laboratory chow and water ad libitum. The study was conducted in accordance with the guidelines set by the European Economic Community (EEC) regulations (revised Directive 86/ 609/ EEC) and was approved by the Ethical Committee at the Faculty of Pharmacy, Cairo University, Egypt.

Egypt. J. Rad. Sci. Applic., Vol. 29, No. 1-2 (2016) 


\section{Irradiation of animals}

Whole body gamma irradiation of rats was carried out at NCRRT using Gamma cell-40 biological irradiator furnished with a Cesium ${ }^{137}\left({ }^{137} \mathrm{Cs}\right)$ source (Atomic Energy of Canada Limited, Ontario, Canada). Rats were exposed to a single radiation dose level of 6Gy (El-Ghazaly and Khayyal, 1995, El-Ghazaly et al., 2010 ${ }^{\mathrm{a}}, 2011^{\mathrm{a}}, 2011^{\mathrm{b}}$ ) delivered at a dose rate of $0.46 \mathrm{~Gy} / \mathrm{min}$.

\section{Drugs and chemicals}

Piperine was purchased from Alfa Aesar, Gmbh \& Co KG, Karlsruche, Germany. All other chemicals and reagents were purchased from SigmaAldrich, St Louis, MO, USA. Enzyme-linked immunosorbent assay (ELISA) rat specific kits for the determination of TNF- $\alpha$ (ID Labs Biotechnology, London, Ontario, Canada) and that for $\mathrm{PGE}_{2}$ (EIAAb Science Co. Ltd, Wuhan, China) were used.

\section{Preparation and administration of piperine}

Piperine was dissolved in saline after being dispersed with Tween-80 (final concentration of Tween-80 is less than 0.1\%) (Li et al., 2007). A pilot study was carried out aiming to determine the optimum anti-inflammatory dose for piperine. It was performed on rats using the carrageenan-induced paw oedema model as an acute inflammatory model. Rats assigned for the pilot study were randomly allocated into 4 groups, each consisting of 8 animals. The groups were then treated as follows: Group I: Received $0.1 \%$ tween 80 orally and served as a control group for piperine treated groups. Groups II, III and IV: Received piperine in doses 10, 20 and $50 \mathrm{mg} / \mathrm{kg}$ given once orally, respectively (Lee et al., 1984, Mujumdar et al., 1990). According to the results obtained from this study, piperine at a dose of $50 \mathrm{mg} / \mathrm{kg}$ gave the highest response of the dose levels tested and was selected for application in the main study.

\section{Experimental Models}

\section{Carrageenan-induced paw oedema and hyperalgesia model}

Evaluation of paw volume and nociceptive threshold was carried out concurrently for the same experimental groups (Fernández-Dueñas et al., 2008 and Sibilia et al., 2006). 


\section{Carrageenan-induced paw oedema}

The model carried out according to the method described by Winter et al. (1962). A volume of $0.1 \mathrm{ml}$ carrageenan suspension (1\%) was injected into the subplantar surface of the right hind paw and the paw volume was measured at $0(\mathrm{Vi})$ and $3 \mathrm{~h}$ after carrageenan injection $\left(\mathrm{V}_{\mathrm{f}}\right)$. The increase in paw volume was measured by a volume displacement method using a water plethysmometer (Panlab Harvard, Barcelona, Spain) and calculated as percentage of oedema compared to the basal paw volume according to the formula: $\%$ of oedema $=$ $\left[\left(\mathrm{V}_{\mathrm{f}}-\mathrm{V}_{\mathrm{i}}\right) / \mathrm{V}_{\mathrm{i}}\right] \times 100$.

\section{Carrageenan-induced hyperalgesia}

The model carried out according to the method described by Randall and Selitto (1957).

The nociceptive thresholds of the hind paw injected with carrageenan were quantified with an analgesy-meter (Ugo Basile, Comerio, Varese, Italy) $3 \mathrm{~h}$ after carrageenan injection.

\section{Six-day old air pouch model}

The model carried out according to the method described by Sedgwick et al. (1984). Briefly an air pouch was produced in the rat by subcutaneous injection of $20 \mathrm{ml}$ sterile air into the intra-scapular area of the shaved back of rats. Two days later, another $10 \mathrm{ml}$ of air was injected at the same site. On the fifth day after the first injection, a further $10 \mathrm{ml}$ of air was injected into the pouch for maintenance of the pouch.

Twenty four hours later (on sixth day), $1 \mathrm{ml}$ of $2 \%$ carrageenan dissolved in saline (Khayyal et al., 2009, Morikawa et al., 2003 and Jain and Parmar, 2011) was injected directly into the pouch and the exudate was collected for estimation of total leucocyte count and assay of biochemical parameters; the exudate level of TBARs and NOx were determined calorimetrically using a spectrophotometer (Unicam 8625, Cambridge, United Kingdom) according to the method of Mihara and Uchiyama (1978) and Miranda et al. (2001), respectively. TNF- $\alpha$ and $\mathrm{PGE}_{2}$ level was measured by an ELISA kit specific for rats using an ELISA plate reader (Dynatech ${ }^{\circledR}$ MR5000, Guernsey, Channel Islands, United Kingdom).

Egypt. J. Rad. Sci. Applic., Vol. 29, No. 1-2 (2016) 


\section{Study design}

Rats were divided into two sets; non-irradiated and irradiated. The later was exposed to a single radiation dose level of $6 \mathrm{~Gy}$; one hour prior to carrageenan injection in the first model and twenty four hours prior to injection of carrageenan in the second model, then each set was divided into three groups ( $\mathrm{n}=8 /$ group): 1 ) Normal group, 2) Inflamed group: Administered $0.1 \%$ tween 80 orally, and 3) Inflamed+ Piperine group: Administered piperine $(50 \mathrm{mg} / \mathrm{kg}$ ) orally; one hour prior to carrageenan injection in the first model and twice orally; twenty four hours and one hour prior to carrageenan injection in the second model.

\section{Statistical analysis}

All data were expressed as mean values \pm standard error of the mean (SEM). Statistical comparisons between different groups were carried out by one-way analysis of variance (ANOVA) followed by Tukey-Kramer multiple comparison test. Statistical analysis was carried out using Graph Pad prism-5 (Graph Pad Software Inc, San Diego, California, USA). A $P$-value $<0.05$ was considered significant. Microsoft Excel program was used for figure representation.

\section{Pilot study}

\section{Results}

Oral administration of piperine in doses of either $10 \mathrm{mg} / \mathrm{kg}$ or $20 \mathrm{mg} / \mathrm{kg}$ to the inflamed rats failed to produce any significant change in the volume of oedema while the dose of $50 \mathrm{mg} / \mathrm{kg}$, resulted in a decrease in paw volume by $44 \%$, as compared to the inflamed group, Table 1 . Accordingly, the subsequent assays were done with piperine at a dose of $50 \mathrm{mg} / \mathrm{kg}$.

TABLE 1. Effect of oral administration of different doses of piperine on the rat paw oedema induced by carrageenan injection.

\begin{tabular}{|c|c|c|c|}
\hline Animals groups & $\mathbf{V}_{\mathbf{i}}(\mathrm{ml})$ & $\mathbf{V}_{\mathbf{f}}(\mathrm{ml})$ & \% of oedema \\
\hline Normal & $1.1 \pm 0.02$ & $1.1 \pm 0.03$ & -- \\
\hline Inflamed (carrageenan 1\%) & $1.06 \pm 0.02$ & $1.39 \pm 0.04$ & $30.8 \pm 1.9$ \\
\hline Inflamed+ piperine $(10 \mathrm{mg} / \mathrm{kg})$ & $1.06 \pm 0.00$ & $1.39 \pm 0.03$ & $31.05 \pm 3.05$ \\
\hline Inflamed+ piperine $(20 \mathrm{mg} / \mathrm{kg})$ & $1.02 \pm 0.02$ & $1.31 \pm 0.05$ & $28.79 \pm 2.80$ \\
\hline Inflamed+ piperine $(50 \mathrm{mg} / \mathrm{kg})$ & $1.05 \pm 0.02$ & $1.23 \pm 0.02$ & $17.21 \pm 1.62^{\#}$ \\
\hline
\end{tabular}

Piperine was administered as a single oral dose $1 \mathrm{~h}$ prior to carrageenan injection. All values were expressed as mean \pm S. E. M. for $n=8 /$ group

${ }^{\#} P<0.05$ compared to inflamed group.

$\mathrm{V}_{\mathrm{i}}$ : Initial paw volume before carrageenan injection.

$\mathrm{V}_{\mathrm{f}}$ : Final paw volume; $3 \mathrm{~h}$ after carrageenan injection. 


\section{Carrageenan-induced paw oedema and hyperalgesia model}

Injection of carrageenan into the right paw resulted in marked oedema formation that led to an increase in the paw volume by $31 \%$ as compared to the initial paw volume $(P<0.05)$ and exposure to radiation before carrageenan injection led to an increase in the paw volume the by $28 \%$ as compared to that of the inflamed non-irradiated group $(P<0.05)$. Oral administration of piperine to the inflamed and inflamed irradiated rats was able to attenuate the paw oedema by $44 \%$ and $45 \%$, respectively as compared to the inflamed and the inflamed irradiated non treated groups $(P<0.05)$, Fig. 1 .

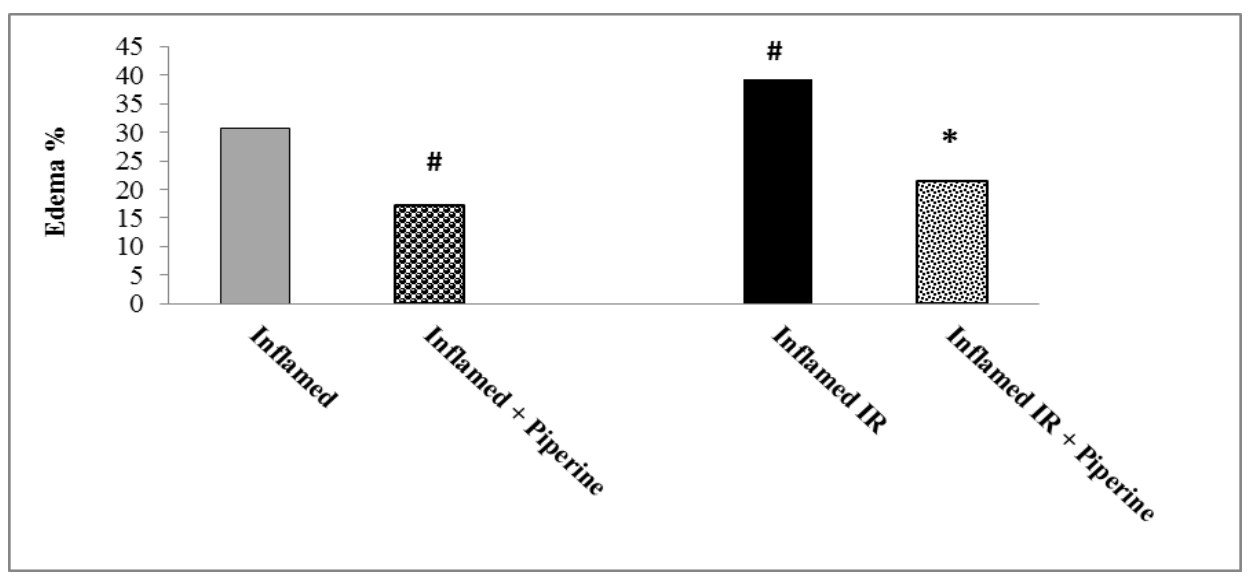

Fig. 1. Effect of oral administration of piperine $(50 \mathrm{mg} / \mathrm{kg}) 1 \mathrm{~h}$ prior to carrageenan injection on the rat paw oedema induced by carrageenan injection in nonirradiated and irradiated rats.

The irradiated rats were exposed to a single acute radiation dose level of $6 \mathrm{~Gy} 1 \mathrm{~h}$ prior to carrageenan injection.

All values were expressed as mean percentage of oedema for $n=8 /$ group.

${ }^{\#} P<0.05$ compared to inflamed group.

${ }^{*} P<0.05$ compared to inflamed irradiated group.

Similarly, injection of carrageenan into the right paw resulted in a marked mechanical hyperalgesia evidenced by the significant decrement in the nociceptive threshold by $57 \%$, as compared to normal group $(P<0.05)$ and exposure to radiation before carrageenan injection caused no significant change in the nociceptive threshold of the inflamed irradiated group as compared to that of the inflamed non-irradiated group $(P<0.05)$. Oral administration of piperine to the inflamed and inflamed irradiated rats increased the nociceptive threshold of both non-irradiated and irradiated rats by $48 \%$ and $50 \%$, respectively, as compared to the inflamed and the inflamed irradiated non treated groups $(P<0.05)$, Fig. 2.

Egypt. J. Rad. Sci. Applic., Vol. 29, No. 1-2 (2016) 


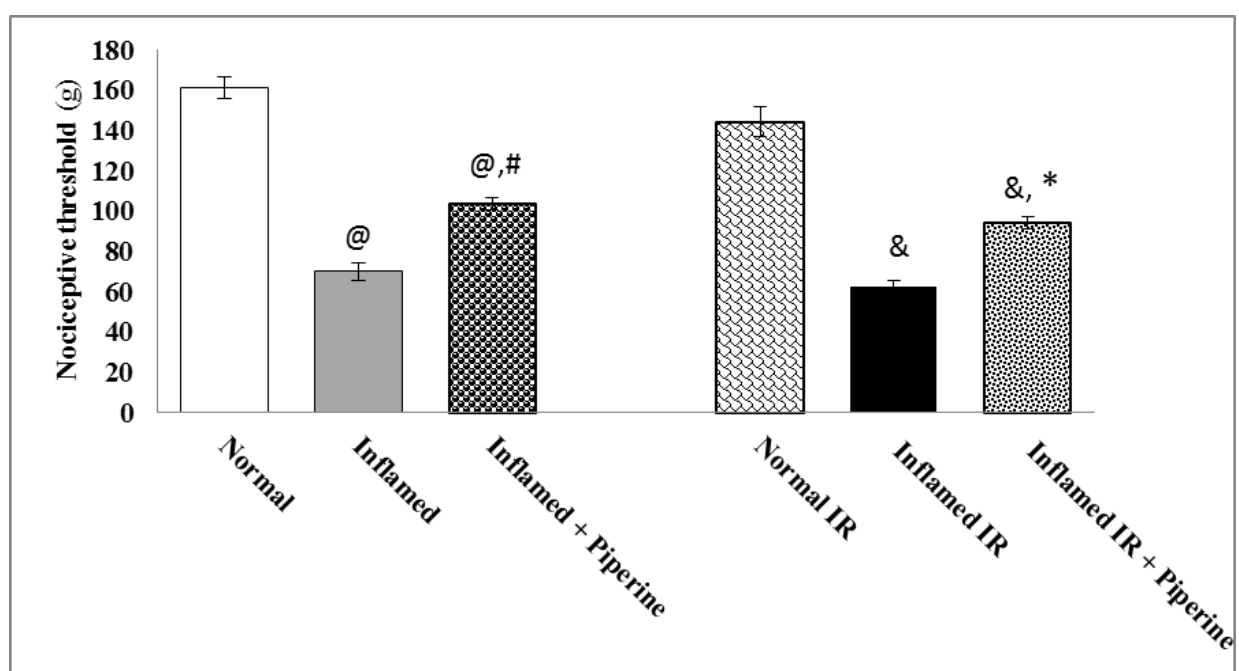

Fig. 2. Effect of oral administration of piperine $(50 \mathrm{mg} / \mathrm{kg}) 1 \mathrm{~h}$ prior to carrageenan injection on the carrageenan-induced hyperalgesia in non-irradiated and irradiated rats.

The irradiated rats were exposed to a single acute radiation dose level of $6 \mathrm{~Gy} 1 \mathrm{~h}$ prior to carrageenan injection.

All values were expressed as mean \pm S. E. M. for $n=8 /$ group.

${ }^{\circledR} P<0.05$ compared to normal.

${ }^{\#} P<0.05$ compared to inflamed group.

${ }^{\circledR} P<0.05$ compared to normal irradiated group.

${ }^{*} P<0.05$ compared to inflamed irradiated group.

\section{Six-day old air pouch model}

Exposure to a single acute radiation dose level of $6 \mathrm{~Gy} 24 \mathrm{~h}$ before carrageenan injection resulted in an increase in the exudation of fluid and the level of leukocyte infiltration by $21 \%$ and $39 \%$, respectively in inflamed irradiated group as compared to the inflamed non-irradiated group $(P<0.05)$. Similarly, the level of TNF- $\alpha, \mathrm{PGE}_{2}$, TBARs, NOx, increased by $57 \%, 15 \%$, $30 \%, 34 \%$, respectively in the inflamed irradiated group as compared to that of the inflamed non-irradiated group $(P<0.05)$. Irradiation of normal rats resulted in an increase in the inflammatory response, yet this increase was not statistically significant, as compared to the normal non-irradiated group $(P<$ 0.05). Accordingly, this group was not treated with piperine.

Oral administration of piperine to the inflamed rats significantly decreased the volume of inflammatory exudate by $34 \%$ and significantly decreased the 
level of leukocyte infiltration, TNF- $\alpha, \mathrm{PGE}_{2}, \mathrm{TBARs}$ and NOx, by $32 \%, 42 \%$, $36 \%, 45 \%$, and $58 \%$, respectively as compared to the inflamed non-treated group $(P<0.05)$, Table 2 .

TABLE 2. Effect of oral administration of piperine on the level of inflammatory mediators estimated in the exudate collected from the six-day old air pouch in non-irradiated rats.

\begin{tabular}{|c|c|c|c|}
\hline Parameters & Normal & Inflamed & Inflamed+ piperine \\
\hline Volume of exudate (ml) & -- & $0.78 \pm 0.02^{@}$ & $0.5 \pm 0.02^{\varrho, \#}$ \\
\hline Total leukocyte count $\left(\times 10^{9}\right)$ & $0.74 \pm 0.05$ & $3.20 \pm 0.27^{@}$ & $2.17 \pm 0.14^{\Theta, \#}$ \\
\hline TNF- $\boldsymbol{\alpha}(\mathrm{pg} / \mathrm{ml})$ & $14.80 \pm 1.28$ & $131.10 \pm 7.66^{@}$ & $76.30 \pm 6.80^{@, \#}$ \\
\hline $\mathbf{P G E}_{2}(\mathrm{pg} / \mathrm{ml})$ & $85.64 \pm 2.33$ & $620.80 \pm 15.66^{@}$ & $397.80 \pm 36.04^{@, \#}$ \\
\hline TBARs $(\mathrm{nmol} / \mathrm{ml})$ & $0.52 \pm 0.01$ & $2.09 \pm 0.19^{\Theta}$ & $1.14 \pm 0.09^{\#}$ \\
\hline NOx (nmol/ ml) & $10.57 \pm 1.01$ & $27.71 \pm 2.38^{@}$ & $11.62 \pm 1.04^{\#}$ \\
\hline
\end{tabular}

Effect of oral administration of piperine $(50 \mathrm{mg} / \mathrm{kg}$ ), given twice, $24 \mathrm{~h}$ and $1 \mathrm{~h}$ before carrageenan injection on the volume of exudate and the level of leukocyte infiltration, TNF- $\alpha, \mathrm{PGE}_{2}$, TBARs, and NOx in the exudate collected from the air pouch of non-irradiated rats.

All values were expressed as mean \pm S. E. M. for $n=8 /$ group.

${ }^{\circledR} P<0.05$ compared to normal.

${ }^{\#} P<0.05$ compared to inflamed group.

TABLE 3. Effect of oral administration of piperine on the level of inflammatory mediators estimated in the exudate collected from the six-day old air pouch in irradiated rats.

\begin{tabular}{|c|c|c|c|}
\hline Parameters & Normal & Inflamed & Inflamed+ piperine \\
\hline Volume of exudate $(\mathrm{ml})$ & -- & $0.95 \pm 0.05^{\&}$ & $0.42 \pm 0.03^{\&, *}$ \\
\hline Total leukocyte count $\left(\times 10^{9}\right)$ & $0.60 \pm 0.09$ & $4.45 \pm 0.26^{\&}$ & $2.46 \pm 0.10^{\&, *}$ \\
\hline TNF- $\boldsymbol{\alpha}(\mathrm{pg} / \mathrm{ml})$ & $54.20 \pm 3.38$ & $206.40 \pm 18.36^{\&}$ & $118.60 \pm 9.56^{\&, *}$ \\
\hline $\mathbf{P G E}_{2}(\mathrm{pg} / \mathrm{ml})$ & $133.10 \pm 18.11$ & $711.50 \pm 30.06^{8}$ & $484.60 \pm 20.93^{\&, *}$ \\
\hline TBARs $(\mathrm{nmol} / \mathrm{ml})$ & $0.36 \pm 0.02$ & $2.72 \pm 0.20^{\&}$ & $1.50 \pm 0.12^{\&, *}$ \\
\hline NOx $(\mathrm{nmol} / \mathrm{ml})$ & $10.77 \pm 0.99$ & $37.06 \pm 1.75^{\&}$ & $17.71 \pm 1.61^{\&, *}$ \\
\hline
\end{tabular}

Effect of oral administration of piperine $(50 \mathrm{mg} / \mathrm{kg}$ ), given twice, $24 \mathrm{~h}$ and $1 \mathrm{~h}$ before carrageenan injection on the volume of exudate and the level of leukocyte infiltration, TNF- $\alpha, \mathrm{PGE}_{2}, \mathrm{TBARs}$ and NOx in the exudate collected from the air pouch of irradiated rats.

The irradiated rats were exposed to a single acute radiation dose level of 6Gy $24 \mathrm{~h}$ prior to carrageenan injection.

All values were expressed as mean \pm S. E. M. for $n=8 /$ group.

${ }^{8} P<.05$ compared to normal irradiated group.

${ }^{*} P<0.05$ compared to inflamed irradiated group.

Egypt. J. Rad. Sci. Applic., Vol. 29, No. 1-2 (2016) 
Similarly, oral administration of piperine to the inflamed irradiated rats significantly decreased the volume of inflammatory exudate by $55 \%$ and significantly decreased the level of leukocyte infiltration, TNF- $\alpha, \mathrm{PGE}_{2}, \mathrm{TBARs}$ and NOx by $45 \%, 43 \%, 31 \%, 45 \%$ and $52 \%$, respectively as compared to the inflamed irradiated non-treated group $(P<0.05)$, Table 3 .

\section{Discussion}

Exposure of rats to a whole body $\gamma$-irradiation resulted in a significant increment in the paw volume of inflamed group as compared to non-irradiated inflamed group. This result is comparable to the previously reported results of Khayyal et al. (2009). This response was attributed to the increase in PG content in tissues following irradiation (Eisen and Walker, 1976 and Yang et al., 2011) and/ or the enhanced release of lysosomal enzymes as a result of disruption of the cell membranes under the influence of radiation (Trocha and Catravas, 1980). Since whole body $\gamma$-irradiation led to significant increment in the paw volume and based on the sensitization theory of Randall and Selitto (1957), the first to make use of the knowledge that inflammation increases sensitivity to pain, it was expected that upon exertion of mechanical hyperalgesia on the inflamed paw of irradiated rats, a significant decrement in the nociceptive threshold would be observed. However, in the present study the elicited response was not in accordance with these theoretical expectations and the nociceptive threshold recorded in the inflamed irradiated rats did not differ significantly from that observed in the inflamed group. The possible underlying mechanism beyond this response was explained in the study of Kereskenyiova and Smajda (2004); their study reported that ionizing radiation would exert an analgesic effect known as "stress-induced analgesia" mediated by the release of endogenous opioids.

As for the six-day old air pouch, it was observed that exposure of animals to radiation resulted in a rise in the volume of exudate collected from the air pouch, which is confirmed by the increased inflammatory cells infiltration. Investigations have been directed to explore the molecular mechanisms by which radiation induces leukocyte recruitment, evidence indicates that cell adhesion molecules (CAM) expression on the surface of endothelial cells is up-regulated following irradiation and consequently acts on leukocytes (Molla and Panes, 2007). The carrageenan-induced rise in exudate level of TNF- $\alpha$ and $\mathrm{PGE}_{2}$ in irradiated rats 
was significantly higher than the rise recorded in non-irradiated rats. These results are in agreement with the findings previously reported in the study of Khayyal et al. (2009). Such an observation may be adequately explained on the ground that IR regulates a wide variety of genes associated with inflammation, especially those producing cytokines such as TNF- $\alpha$ (Linard et al., 2004 and Sherman et al., 1991). As for $\mathrm{PGE}_{2}$, the radiation-induced cyclooxygenase-2 (COX-2) expression would be paralleled by increased $\mathrm{PGE}_{2}$ synthesis (Khayyal et al., 2009 and Yang et al., 2011).

Results indicated that the exudate level of TBARs and NOx in inflamed irradiated rats was significantly higher than the rise recorded in inflamed nonirradiated rats. These results are in agreement with those reported in the study of Mckinney et al. (1998) and Khayyal et al. (2009). Overproduction of reactive oxygen species (ROS) upon irradiation followed by carrageenan injection was previously attributed to the increase in the formation of the main product of lipid peroxidation; malondialdehyde (El-Ghazaly et al., 2010, $2010^{\mathrm{b}}$ and Khayyal et al., 2009). Radiation exposure potentiates the NOx production in the inflamed rats by a process involving the induction of TNF- $\alpha$ with subsequent increase in the inducible nitric oxide synthase (iNOS) gene expression which paralleled the increase in nitric oxide (NO) production (Mckinney et al., 1998). Moreover, the augmentation of NOx production in inflamed rats after exposure to radiation could be attributed to the action of ROS (Ibuki and Goto, 1997) and to the activation of signal transduction involving nuclear factor-kappa B (NF-кB) which lead to macrophage activation-induced NO production (Ibuki and Goto, 2004).

The results of the present study revealed the anti-inflammatory effect of piperine on carrageenan-induced paw oedema in both non-irradiated and irradiated rats. In the pilot study, a significant anti-oedemic activity of piperine was observed at an oral dose of $50 \mathrm{mg} / \mathrm{kg}$. This is consistent with the earlier study of Lee et al. (1984) in which the anti-inflammatory activity of piperine was reported at the same dose. However, Mujumdar et al. (1990) showed that piperine can act as an anti-oedemic agent at a dose as low as $10 \mathrm{mg} / \mathrm{kg}$, in their study the anti-oedemic activity of piperine was mediated through histamine and serotonin inhibition. Moreover, Sudjarwo (2005) reported that piperine-induced reduction in the paw oedema was accompanied by a concomitant reduction in $\mathrm{PGE}_{2}$ level in the paw exudate; thus the anti-inflammatory effect of piperine may be attributed Egypt. J. Rad. Sci. Applic., Vol. 29, No. 1-2 (2016) 
to the inhibition of PG release. Another possible mechanism that might be involved in the anti-inflammatory activity of piperine on carrageenan-induced paw oedema is the suppression of the lysosomal enzymes activities; the detailed mechanism of this suppression was reported by Murunikkara et al. (2012) who suggested that the suppression of lysosomal enzymes after piperine treatment might be due to its stabilizing effect on the lysosomal membranes.

In order to investigate the analgesic activity of piperine; its ability to attenuate the mechanical hyperalgesia of the inflamed paw of both non-irradiated and irradiated rats was evaluated. Results indicated that oral administration of piperine resulted in a significant increment in the nociceptive threshold. These findings are supported by those of Bang et al. (2009); who reported that piperinetreated rats could tolerate higher pressure on the affected paw as compared to the non-treated ones, where they attributed the analgesic activity of piperine to the inhibition of $\mathrm{PGE}_{2}$ which is directly involved in triggering pain. However, Sudjarwo (2005) showed that piperine at oral doses $2.5,5,10 \mathrm{mg} / \mathrm{kg}$ has no analgesic properties using the hot-plate and acetic acid-induced writhing tests.

The carrageenan air pouch model was employed in the current work to elucidate the pharmacological effect of piperine on the production of proinflammatory mediators; where the oral administration of piperine was found to produce a significant decrement in the exudate volume and leukocyte infiltration as well as the exudate levels of TNF- $\alpha, \mathrm{PGE}_{2}$, TBARs, and NOx in both nonirradiated and irradiated rats. Similarly, the study of Umar et al. (2013) have demonstrated that the anti-arthritic and anti-oxidative activity of piperine in collagen-induced arthritis, an experimental model of rheumatoid arthritis, were mediated through the inhibition of pro-inflammatory mediators including TNF- $\alpha$, IL-1 $\beta, \mathrm{PGE}_{2}$, NO with subsequent inhibition to the accumulation and activation of poly morpho-nuclear cells and by enhancing the activity of anti-oxidant enzymes.

The possible underlying mechanism beyond the anti-inflammatory effect of piperine has been investigated in several in vitro studies and has been attributed to its inhibitory effect on NF-אB; the study of Kumar et al. (2007) demonstrated that piperine has a potent inhibitory effect on TNF- $\alpha$ induced expression of cell adhesion molecules viz; ICAM-1, VCAM-1, and E-selectin; an effect that was attributed to its ability to inhibit the translocation and activation of NF-kB. Moreover, the study of Ying et al. (2013) found that 
piperine significantly inhibited TNF- $\alpha, \mathrm{PGE}_{2}$ and NO-production in lipopolyscharide (LPS) stimulated macrophages; this inhibition was attributed to the suppression of gene and protein expression of TNF- $\alpha$, COX-2, and iNOS via inhibition of NF- $\mathrm{KB}$ activation. The involvement of NF- $\mathrm{KB}$ inhibition in the mechanism of the anti-inflammatory effect of piperine was also confirmed in the study of Vaibhav et al. (2012) who reported that piperine suppresses cerebral ischemia-reperfusion-induced inflammation through the repression of COX-2, iNOS, and NF-kB in middle cerebral artery occlusion rat model.

Concerning its observed anti-oxidant activity, herein, piperine has been demonstrated in a variety of studies to protect against oxidative damage. The in vitro study of Mittal and Gupta (2000) has reported the protective effect of piperine against oxidative damage by inhibiting or quenching free radicals and ROS with a subsequent inhibition of lipid peroxidation. On the same line, the study of Selvendiran et al. (2004) revealed that oral supplementation of piperine effectively suppressed lung carcinogenesis in mice as evidenced by a decrease in the extent of mitochondrial lipid peroxidation and concomitant increase in the activities of anti-oxidants enzymes (Superoxide dismutase, catalase, and glutathione peroxidase) and the non-enzymatic anti-oxidants (GSH, vitamin E, and vitamin C) levels when compared to untreated lung carcinogenesis bearing animals.

In conclusion, piperine possesses potential anti-inflammatory and analgesic activities probably through down-regulation of the pro-inflammatory mediators.

\section{References}

Bang, J. S., Oh D. H., Choi, H. M., Sur, B. J., Lim, S. J., Kim, J. Y., Yang, H. I., Yoo, M. C., Hahm, D. H. and Kim, K. S. (2009) Anti-inflammatory and antiarthritic effects of piperine in human interleukin $1 \beta$-stimulated fibroblastlike synoviocytes and in rat arthritis models. Arthritis Res. Ther., 11, R49.

Brower, V. (1998) Nutraceuticals: poised for a healthy slice of the healthcare market. Nat. Biotechnol., 16, 728.

Eisen, V. and Walker, D. I. (1976) Effect of ionizing radiation on prostaglandin-like activity in tissues. Br. J. Pharmacol., 57, 527.

El-Ghazaly, M. A. and Khayyal, M. T. (1995) The use of aqueous propolis extract against radiation-induced damage. Drugs Exp. Clin. Res., 21, 229.

El-Ghazaly, M. A., Gharib, O. A., El-Sheikh M. M. and Khayyal, M. T. (2015) The protective role of ginkgo biloba against radiation induced injury on rat gastro-intestinal tract. Egypt. J. Rad. Sci. Applic., 28, 1.

Egypt. J. Rad. Sci. Applic., Vol. 29, No. 1-2 (2016) 
El-Ghazaly, M. A., Kenawy, S. A., Nada, A. S. and Hegazy, M. E. (2010 ${ }^{\text {a }}$ The potential therapeutic effect of curcumin on the adjuvant-induced arthritis in irradiated rats. Egypt. J. Rad. Sci. Applic., 23, 317.

El-Ghazaly, M. A., Nada, A. S., El-Hazek, R. M. and Khayyal, M. T. (2010 ${ }^{\text {b) Effect }}$ of selective COX-2 inhibitor, celecoxib on adjuvant-induced arthritis model in irradiated rats. Int. J. Radiat. Biol., 86, 1079.

El-Ghazaly, M. A., Rashed, R. R. and Khayyal, M. T. (2011 $\left.{ }^{\text {b }}\right)$ Anti-ulcerogenic effect of aqueous propolis extract and the influence of radiation exposure. Int. J. Radiat. Biol., 87, 1045.

El-Ghazaly, M.A., El-Naby, D.H. and Khayyal, M.T. (2011 ${ }^{\text {a }}$ ) The influence of irradiation on the potential chondroprotective effect of aqueous extract of propolis in rats. Int. J. Radiat. Biol., 87, 254.

Fernández-Dueñas, V., Sánchez, S., Planas, E. and Poveda, R. (2008) Adjuvant effect of caffeine on acetylsalicylic acid anti-nociception: prostaglandin $E_{2}$ synthesis determination in carrageenan-induced peripheral inflammation in rat. Eur. J. Pain, 12, 157.

Ibuki, Y. and Goto, R. (1997) Enhancement of NO production from resident peritoneal macrophages by in vitro gamma-irradiation and its relationship to reactive oxygen intermediates. Free Radic. Biol. Med., 22, 1029.

Ibuki, Y. and Goto, R. (2004) Ionizing radiation-induced macrophage activation: augmentation of nitric oxide production and its significance. Cell. Mol. Biol. (Noisy-le-grand), 50, OL617.

Jain, M. and Parmar, H. S. (2011) Evaluation of antioxidative and anti-inflammatory potential of hesperidin and naringin on the rat air pouch model of inflammation. Inflamm. Res., 60, 483.

Kalra, E. K. (2003) Nutraceutical--definition and introduction. AAPS PharmSci., 5, E25.

Keele, C. A. (1967) The chemistry of pain production. Proc. R. Soc. Med., 60, 419.

Kereskenyiova, E. and Smajda, B. (2004) Endogenous opioids and analgesic effects of ionizing radiation in rats. Acta. Vet. Brno., 73, 195.

Khayyal, M.T., El-Ghazaly, M. A., El-Hazek, R. M. and Nada, A. S. (2009) The effects of celecoxib, a COX-2 selective inhibitor, on acute inflammation induced in irradiated rats. Inflammopharmacology, 17, 255.

Kumar, S., Singhal, V., Roshan, R., Sharma, A., Rembhotkar, G. W. and Ghosh, B. (2007) Piperine inhibits TNF- $\alpha$ induced adhesion of neutrophils to endothelial monolayer through suppression of NF-kappaB and IkappaB kinase activation. Eur. J. Pharmacol., 575, 177.

Kumar, V., Abbas, A., Fausto, N. and Aster, J. (2012) Inflammation and repair. In Robbins Basic Pathology. Edited by V.Kumar, A.Abbas, N.Fausto and J.Aster. Philadelphia, Elsevier, pp. 44-52. 
Lee, E. B., Shin, K. H. and Woo, W. S. (1984) Pharmacological study on piperine. Arch. Pharmac. Res., 7, 127.

Li, S., Wang, C., Wang, M., Li, W., Matsumoto, K. and Tang, Y. (2007) Antidepressant like effects of piperine in chronic mild stress treated mice and its possible mechanisms. Life Sci., 80, 1373.

Linard, C., Marquette, C., Mathieu, J., Pennequin, A., Clarencon, D. and Mathe, D. (2004) Acute induction of inflammatory cytokine expression after $\gamma$-irradiation in the rat: Effect of NF-kB inhibitor. Int. J. Radiat. Oncol. Biol. Phys., 58, 427.

Linley, J. E., Rose, K., Ooi, L. and Gamper, N. (2010) Understanding inflammatory pain: ion channels contributing to acute and chronic nociception. Pflugers Arch., 459, 657.

Mckinney, L. C., Aquilla, E. M., Coffin, D., Wink, D. A. and Vodovotz, Y. (1998) Ionizing radiation potentiates the induction of nitric oxide synthase by IFN- $\gamma$ and/or LPS in murine macrophage cell lines: role of TNF- $\alpha$. J. Leukoc. Biol., 64, 459.

Mihara, M. and Uchiyama, M. (1978) Determination of malondialdehyde precursor in tissues by thiobarbituric acid test. Anal. Biochem., 86, 271.

Miranda, K. M., Espey, M. G. and Wink, D. A. (2001) A rapid, simple spectrophotometric method for simultaneous detection of nitrate and nitrite. Nitric Oxide, 5, 62.

Mittal, R. and Gupta, R. L. (2000) In vitro antioxidant activity of piperine. Methods Find Exp. Clin. Pharmacol., 22, 271.

Molla, M. and Panes, J. (2007) Radiation-induced intestinal inflammation. World J. Gastroenterol., 13, 3043.

Morikawa, K., Nonaka, M., Torii, I. and Morikawa, S. (2003) Modulatory effect of fosfomycin on acute inflammation in the rat air pouch model. Int. J. Antimicrob. Agents, 21, 334.

Mujumdar, A. M., Dhuley, J. N., Deshmukh, V. K., Raman, P. H. and Naik, S. R. (1990) Anti-inflammatory activity of piperine. Jpn. J. Med. Sci. Biol., 43, 95.

Murunikkara, V., Pragasam, S. J., Kodandaraman, G., Sabina, E. P. and Rasool, M. (2012) Anti-inflammatory effect of piperine in adjuvant-induced arthritic rats-a biochemical approach. Inflammation, 35, 1348.

Randall, L. O. and Selitto, J. J. (1957) A method for measurement of analgesic activity on inflamed tissue. Arch. Int. Pharmacodyn. Ther., 111, 409.

Ryan, G. B. (1974) Inflammation: Mediators of inflammation. Beitr Pathol., 152, 272.

Ryan, G. B. and Majno, G. (1977) Acute inflammation. A review. Am. J. Pathol., 86, 183.

Sabina, E. P., Nagar, S. and Rasool, M. (2011) A role of piperine on monosodium urate crystal-induced inflammation. An experimental model of gouty arthritis. Inflammation, 34, 184.

Egypt. J. Rad. Sci. Applic., Vol. 29, No. 1-2 (2016) 
Sedgwick, A. D., Sin, Y. M., Mackay, A. R., Al-Duaij, A. and Willoughby, D. A. (1984) Studies of the mode of action of non-steroidal anti-inflammatory drugs using a model of facsimile synovium. J. Pharm. Pharmacol., 36, 171.

Selvendiran, K., Senthilnathan, P., Magesh, V. and Sakthisekaran, D. (2004) Modulatory effect of piperine on mitochondrial antioxidant system in benzo(a)pyrene-induced experimental lung carcinogenesis. Phytomedicine, 11, 85.

Sherman, M. L., Datta, R., Hallahan, D. E., Weicheselbaum, R. R. and Kufe, D. W. (1991) Regulation of tumor necrosis factor gene expression by ionizing radiation in human myeloid leukemia cells and peripheral blood monocytes. J. Clin. Invest., 87, 1794.

Sibilia, V., Lattuada, N., Rapetti, D., Pagani, F., Vincenza, D., Bulgarelli, I., Locatelli, V., Guidobono, F. and Netti, C. (2006) Ghrelin inhibits inflammatory pain in rats: involvement of the opioid system. Neuropharmacology, 51, 497.

Sudjarwo, S.A. (2005) The potency of piperine as anti-inflammatory and analgesic in rats and mice. Folia. Medica., 41, 190.

Trocha, P. J. and Catravas, G. N. (1980) Prostaglandin levels and lysosomal enzyme activities in irradiated rats. Int. J. Radiat. Biol. Relat. Stud. Phys. Chem. Med., 38, 503.

Umar, S., Golam, Sarwar, A. H., Umar, K., Ahmad, N., Sajad, M., Ahmad, S., Katiyar, C. K. and Khan, H. A. (2013) Piperine ameliorates oxidative stress, inflammation and histological outcome in collagen induced arthritis. Cell. Immunol., 284, 51.

Vaibhav, K., Shrivastava, P., Javed, H., Khan, A., Ahmed, M. E., Tabassum, R., Khan, M. M., Khuwaja, G., Islam, F., Siddiqui, M. S., Safhi, M. M. and Islam, F. (2012) Piperine suppresses cerebral ischemia-reperfusion-induced inflammation through the repression of COX-2, NOS-2, and NF-kappaB in middle cerebral artery occlusion rat model. Mol. Cell. Biochem. 367, 73.

Winter, C. A., Risley, E. A. and Nuss, G. W. (1962) Carrageenan-induced paw edema in hind paw of the rat as an assay for anti-inflammatory drugs. Proc. Soc. Exp. Biol. Med., 111, 544.

Yang, H. J., Youn, H., Seong, K. M., Yun, Y. J., Kim, W., Kim, Y. H., Lee, Y. J., Kim, C. S., Jin, Y. W. and Youn, B. (2011) Psoralidin, a dual inhibitor of COX-2 and 5-LOX, regulates ionizing radiation (IR)-induced pulmonary inflammation. Biochem. Pharmacol., 82, 524.

Ying, X., Yu, K., Chen, X., Chen, H., Hong, J., Cheng, S. and Peng, L. (2013) Piperine inhibits LPS induced expression of inflammatory mediators in RAW 264.7 cells. Cell. Immunol., 285, 49.

(Received: 15/08/2016;

accepted: 04/09/2016)

Egypt. J. Rad. Sci. Applic., Vol. 29, No. 1-2 (2016) 


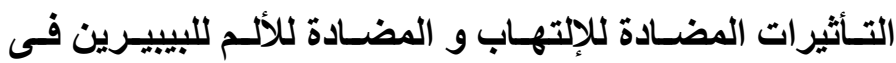

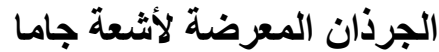

$$
\begin{aligned}
& \text { منى عبد اللطيف الغزالى ، و نهى عبد الفتاح فاضل ، و إنجى رفعت راشد ، و }
\end{aligned}
$$

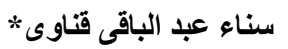

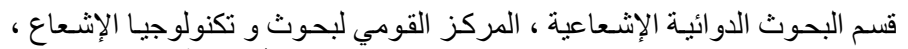

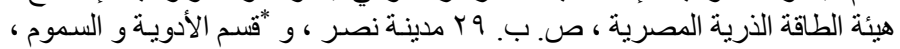

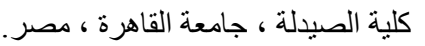

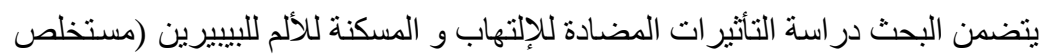

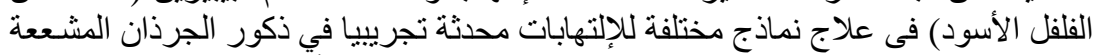

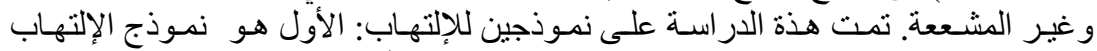

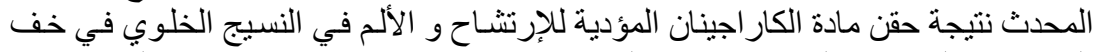

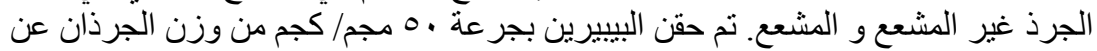

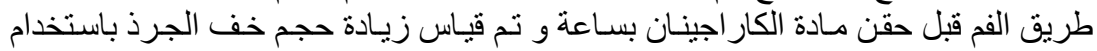

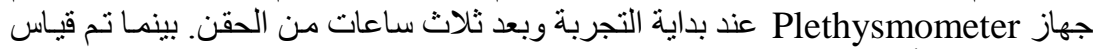

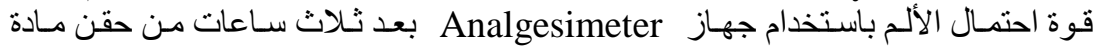

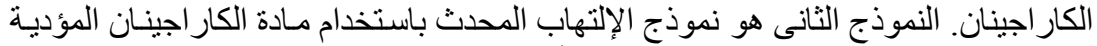

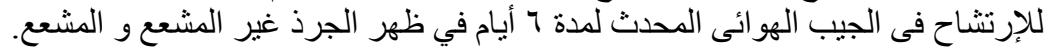

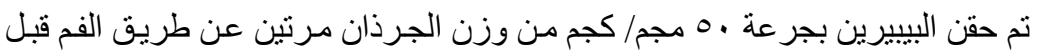

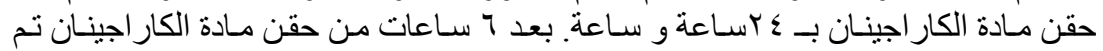

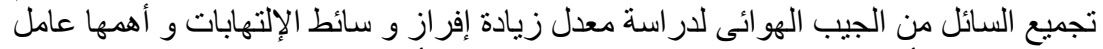

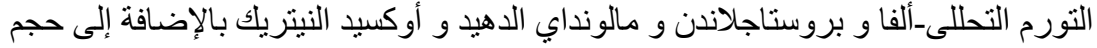

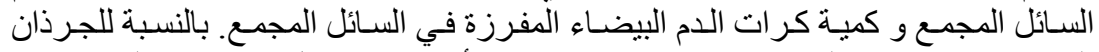

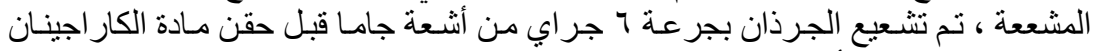

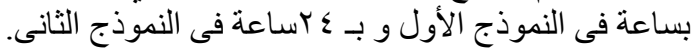

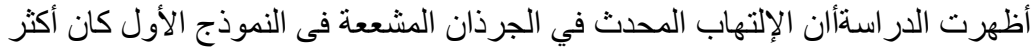

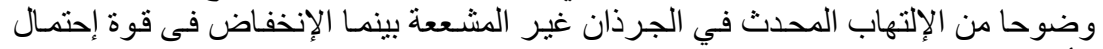

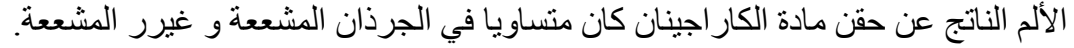

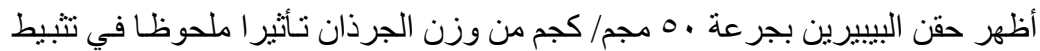

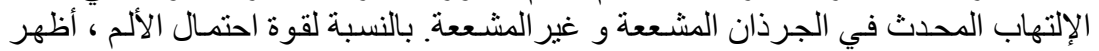

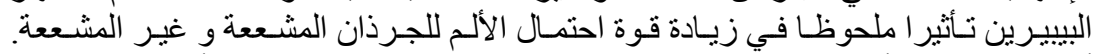

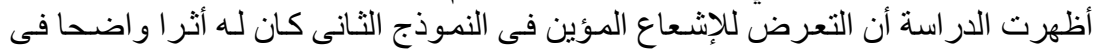

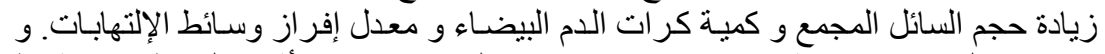

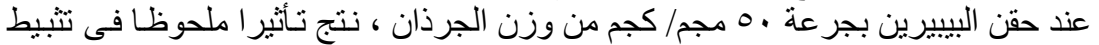

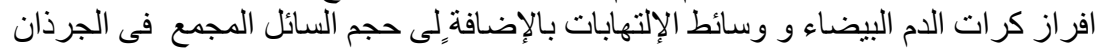

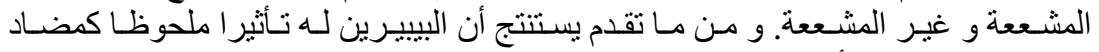

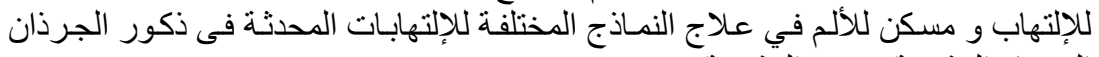

Egypt. J. Rad. Sci. Applic., Vol. 29, No. 1-2 (2016) 